\title{
ANATOMIA DA MADEIRA DE Colletia paradoxa (Spreng.) Escalante
}

Josē Newton Cardoso Marchiori

Departamento de Ciências Florestais. Centro de Ciēncias Rurais. UFSM. Santa Maria, RS.

RESUMO

0 trabalho trata da descrição das características gerais, macroscópicas e microscópicas da madeira de Colletia paradoxa (Spreng.) Escalante, arbusto āfilo e xerōfilo da flora sulriograndense.

Foram observados poros de diāmetro muito pequeno, vasos muito curtos com espessamentos espiralados e placas de perfuração sim ples, fibras libriformes não septadas, parēnquima axial paratraqueal escasso, e raios Heterogēneos de tipo II, com freqdentes cēlulas per furadas de raio.

A ocorrência de células perfuradas de raio e as caracterís ticas de elementos vasculares são discutidas com base em aspectos eco-fisiológicas da planta e informações anatōmicas da literatura.

SUMMARY

MARCHIORI, J.N.C. Wood anatomy of Colletia paradoxa (Spreng.) Esca lante. Ciência e Natura, 5: 161-170.

This paper deals with the description of general, macrosco pic and microscopic anatomy of Colzetia paradoxa (Spreng.) Escalan te, an aphyllous and xerophilous shrub from Rio Grande do Sul (Bra zi 1).

Pores of very small diameter, very short vessel elements, spiral thickenings and simple perforation plates in vessels, non sptate libriform fibres, scanty paratracheal axial paranchyma, and Heterogeneous II rays were observed in the wood.. Perforated cells are also common in rays.

The presence of perforated ray cells and anatomical features of the vessel elements are discussed with respect to eco-physiological aspects of the plant and wood anatomy literature.

INTRODUÇAOO

o gênero Colzetia Commerson (Rhamnaceae) compreende cerca de 17 espécies de arbustos āfilos ou sub-āfilos da América do Sul austral. No sul do Brasil e no Estado do Rio Grande do Sul o gênero encontra-se representado por apenas duas espēcies:

Colzetia paradoxa (Spreng.) Escalante, que é objeto deste estudo ē um arbusto muito ramoso, de atē $3 \mathrm{~m}$ de altura, āfilo quan do adulto, e de aparēncia inconfundīvel devido a suas ramificações grisāceas, triangulares, agudas e em disposição oposta-cruzada. Toda 
a planta repete esta organização que lembra uma cruz de espinhos. Cresce em solos arenosos, montanhas e campos pedregosos, sendo en contrada no Rio Grande do Sul notadamente na região fisiogrāfica da Serra do sudeste. A iēm do Brasil, ocorre com frequência nos Departa mentos do sul da Repūblica Oriental do Uruguai (LOMBARDO, 7) e na Província de Buenos Aires, na zona serrana de Balcarce e Lobería (BUR KART, 3).

A xilologia do gênero Colzetia é das menos conhecidas den tro da familia Rhamnaceae. Is to se deve, provavelmente, ao pequeno porte de suas espécies, fato limitante a uma maior utilização do le nho.

A madeira de colletia paradoxa não è descrita na literatu ra anatômica referente a esta famîlia botânica. O presente trabalho, além da descrição do lenho, procura comparar a estrutura desta ma deira com a de outras espécies taxonomicamente afins e correlacionarcer tas características anatōmicas com a xeromorfia da planta.

REVISAOO DA LITERATURA

As madeiras do gênero Colzetia são pouco conhecidas, haven do poucas referências na literatura sobre suas caracterîsticas ana tômicas.

RECORD \& HESS (12) relacionam alguns caracteres gerais e organolépticos da madeira de colzetia spinosa Lam., tais como cor amarelada, britho mediano, textura fina, ausência de odor e gosto, grã bastante reta, e elevado peso específico, dureza e resistência.

Em outro trabalho, RECORD (10) fornece uma descrição ana tômica da mesma espécie, baseado em uma amostra de madeira (Yale 34053), coletada no sul do Chile: "Anëis de crescimento presente;ma deira de porosidade mais ou menos em anel. Poros pequenos e muito pequenos, não visíveis individualmente sem lente, numerosos; em sua maioria em agrupamentos racemiformes arranjados em faixas diagonais ou zig-zag. Vasos com espessamentos espiralados. Raios com 1 a 5 , algumas vezes atē 8 , células de largura e até mais do que 50, comu mente menos de 30 cēlulas de altura; heterogêneos, pelo menos em par te; cristais frequentes; pontuações rädio-vasculares pequenas, arre dondadas. Parênquima axial. paratraqueal, não muito abundante; séries cristalifferas ocasionalmente presentes. Fibras lenhosas com paredes muito espessas, gelatinosas e com pontuações diminutas".

METCALFE \& CHALK (8) citam para o gênero, entre outras ca racterísticas, a presença de placas de perfuração exclusivamente sim ples e ausência de tiloses.

MATERIAL E METODOS

A amostra de madeira estudada neste trabalho é procedente 
do municīpio de Canguçū, RS, e encontra-se registrada na xiloteca do Departamento de Ciências Florestais son o nọ 261. O material foi co 1hido por Longhi em 1981, e a exsicata tem o nūmero HDCF 581.

As secções anatômicas da madeira foram coloridas com safra nina e azul de astra, e montadas em lâminas permanentes com "entellan". 0 material macerado da madeira foi colorido com safranina.

Os dados quantitativos dos elementos celulares constituin tes da madeira foram obtidos conforme as recomendações da COPANT(6), com as modificações adotadas por BURGER (2), e são apresentadas na Tabela I. As fotomicrografias foram tomadas em aparelho Carl Zeiss.

TABELA I. DADOS QUANTITATIVOS DA ESTRUTURA ANATÔMICA DO XILEMA SECUN DARIO DE Colzetia paradoxa.

\begin{tabular}{|c|c|c|c|c|}
\hline CARACTERISTICA ANATŌMICA & $\begin{array}{c}\text { VALOR } \\
\text { MIN. }\end{array}$ & MEDIA & $\begin{array}{c}\text { VALOR } \\
\text { MĀX. }\end{array}$ & $\begin{array}{l}\text { DESVIO } \\
\text { PADRAO }\end{array}$ \\
\hline 1. C. elementos vasculares ( $\mu \mathrm{m})$ & 187,5 & 264,20 & 340,0 & 36,67 \\
\hline 2. C. apēndices elem. vasculares $(\mu \mathrm{m})$ & 10,0 & 39,05 & 80,0 & 21,74 \\
\hline 3. $\emptyset$ tangencial de poros $(\mu \mathrm{m})$ & 17,5 & 32,05 & 42,5 & 6,05 \\
\hline 4. H. raios multi-seriados ( $\mu \mathrm{m})$ & 147,5 & 465,45 & 1005,0 & 194,88 \\
\hline 5. H. raios multi-seriados (células) & 6,0 & 25,00 & 52,0 & 11,81 \\
\hline 6. L. raios multi-seriados $(\mu \mathrm{m})$ & 12,5 & 34,25 & 65,0 & 11,74 \\
\hline 7. L. raios multi-seriados (células) & 2,0 & 4,0 & 7,0 & 1,40 \\
\hline 8. H. raios uni-seriados $(\mu \mathrm{m})$ & 57,5 & 152,15 & 425,0 & 70,80 \\
\hline 9. H. raios uni-seriados (cēlulas) & 1,0 & 4,90 & 15,0 & 2,79 \\
\hline 10. L. raios uni-seriados $(\mu \mathrm{m})$ & 7,5 & 10,80 & 17,5 & 2,75 \\
\hline 11. Raios/mm & 13,0 & 16,12 & 19,0 & 1,48 \\
\hline 12. C. de fibras ( $\mu \mathrm{m})$ & 666,4 & 828,10 & 1048,6 & 96,00 \\
\hline 13. $\emptyset$ total de fibras $(\mu \mathrm{m})$ & 7,5 & 10,98 & 15,0 & 1,62 \\
\hline 14. $\emptyset$ do lumem de fibras ( $\mu \mathrm{m})$ & 1,3 & 2,53 & 3,8 & 0,64 \\
\hline 15. E. parede de fibras $(\mu \mathrm{m})$ & 2,5 & 4,22 & 6,3 & 0,75 \\
\hline 16. C. Células Parēnquimas Axiais $(\mu \mathrm{m})$ & 90,0 & 112,20 & 162,5 & 20,93 \\
\hline 17. C. Sēries Parēnquimas Axiais ( $\mu \mathrm{m})$ & 175,0 & 224,4 & 287,5 & 39,77 \\
\hline 18. Fração de poros (\%) & 12,0 & 17,40 & 23,0 & 4,16 \\
\hline 19. Fração de raios (\%) & 20,0 & 25,0 & 28,0 & 4,00 \\
\hline २०. Fração de parēnquima axial (\%) & 4,0 & 6,0 & 9,0 & 2,12 \\
\hline 21. Fração de fibras (\%) & 45,0 & 51,60 & 54,0 & 3,83 \\
\hline
\end{tabular}

\section{DESCRIÇAOO DA MADEIRA}

Caracteres gerais e organolépticos

Madeira de cerne e alburno distintos, sem brilho, se odor e gosto característicos, de grã direita, dura e de textura fina. A 1 
burno estreito, de cor amarelada; cerne de cor castanho-escuro.

Caracteres macroscópicos

Poros: invisíveis a olho nū, muito pequenos, numerosos, sem conteū dos, em distribuição semi-difusa; poros agrupados em estreita e des continua faixa no inīcio do anel de crescimento e, principalmente, em agrupamentos diagonais ao longo do anel. Linhas vasculares ret lineas.

Parênquima axiaz: Paratraqueal, pouco abundante. As linhas tangenci ais e diagonais de cor mais clara do que o tecido fibroso, vistas em plano transversal, são resultantes da associação de parênquima axial e poros.

Parênquima radial: Raios invisíveis a olho nū em secção transversal, finos, muito numerosos. Em plano longitudinal tangencial, visiveis com dificuldade sob lente, baixos, não estratificados. Espelhado dos raios pouco contrastado.

Anéis de crescimento: Distintos, individualizados pela formação de uma faixa descontínua e estreita de poros e parênquima axial no in cio do anel de crescimento.

outros caracteres: Canais secretores, liber incluso e mäculas medula res, ausentes.

Caracteres microscópicos

Vasos: Porosidade semi-difusa. Poros correspondendo a $17,4 \%$ do volu me da madeira, distribuídos em agrupamento tangencial descontinuo e estreito de poros no inicio do anel de crescimento e, mais notadamen te, em agrupamentos diagonais de poros (Figura la); extremamente nu merosos, de diāmetro muito pequeno $(17,5-32-42,5 \mu \mathrm{m})$, de secção poligonal, paredes delgadas, e sem conteúdos.

Elementos vasculares muito curtos $(187,5-264-340 \mu \mathrm{m}$

de comprimento), com apêndices curtos (10 - 39 - $80 \mu \mathrm{m})$ em uma ou

em ambas extremidades. Vasos com espessamentos espiralados, placas de perfuração simples, e sem conteúdos.

Pontuado intervascular alterno. Pontuações intervasculares de forma oval, pequenas, não ornamentadas; com abertura horizontal, inclusa e lenticular. Pontuações rádio-vasculares e parênquimo-vas culares, pequenas e arredondadas, menores de $10 \mu \mathrm{m}$.

Parênquima axial: Escasso, ocupando cerca de $6 \%$ do volume da madei ra, paratraqueal, em sēries verticais não estratificadas de 175 224 - $287 \mu \mathrm{m}$ e, geralmente, compostas de 2 cēlulas de altura.

Parênquima radiaz: Ocupando cerca de $25 \%$ do volume da madeira. Raios de ti po normal, ocasionalmente fusionados, heterogēneos de tipo II (Figu ra 1b), muito numerosos (13-16-19 raios/mm) (Figura 1c). 

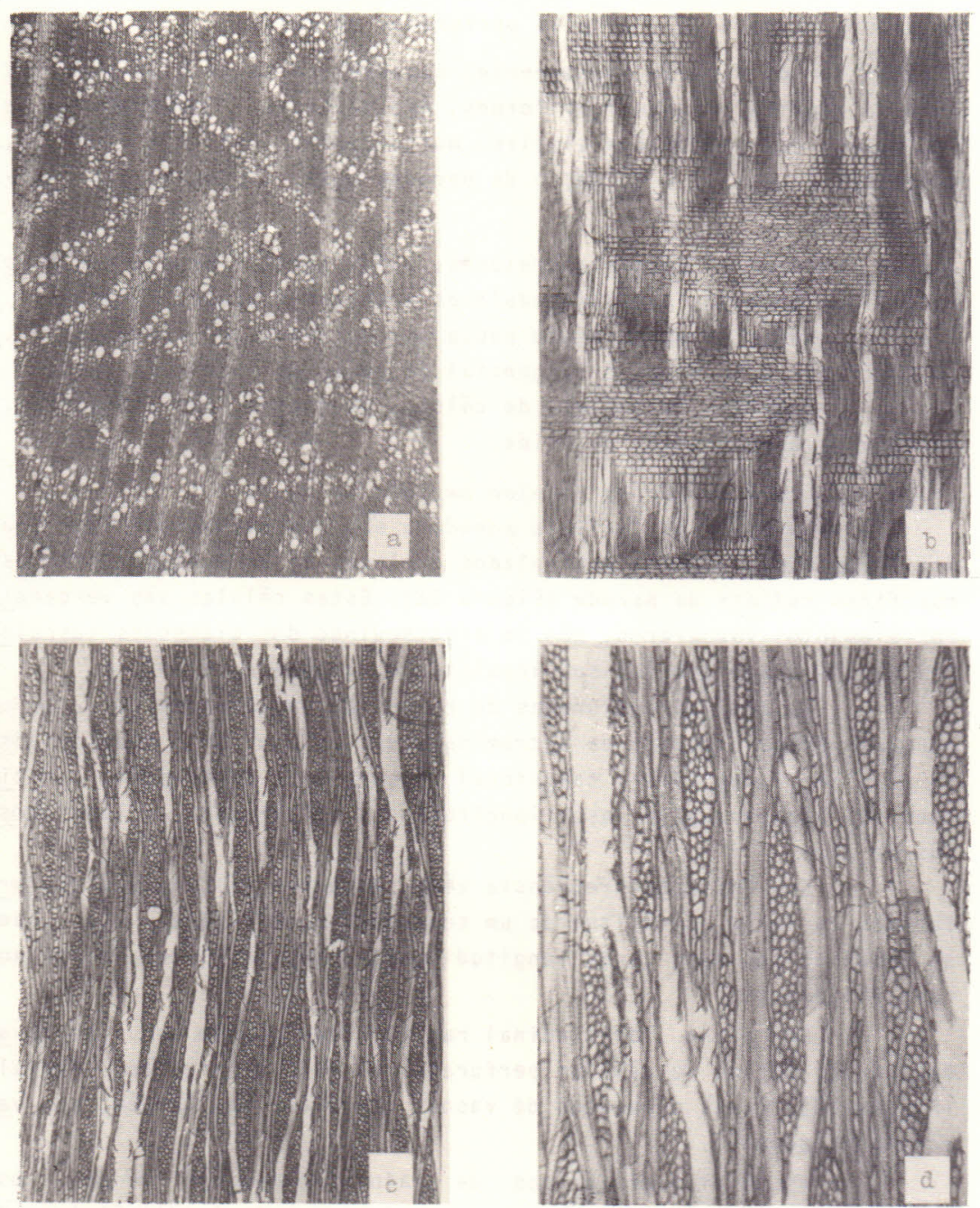

Figura 1. a, secção transversal ( $32 \mathrm{x})$, mostrando poros em agrupamen tos diagonais e raios largos. b, raios heterogēneos em secção longitudinal radial $(32 x)$. c, corte longitudinal tangencial $(32 \mathrm{x})$. d, corte longitudinal tangencial (72 X).

Raios uni-seriados pouco frequentes, extremamente finos $(7,5-10,8-17,5 \mu \mathrm{m})$, extremamente baixos $(57,5-152-425 \mu \mathrm{m}) \mathrm{e}$ com 1 - 5 - 15 células de altura. Raios multi-seriados finos $(12,5-$ $34-65 \mu \mathrm{m})$ e com $2-4-7$ cēlulas de largura; de extremamente bai xos a muito baixos $(147,5-465$ - $1005 \mu \mathrm{m})$ e com 6 - 25 - 52 cêlulas 
de altura (Figura ld). Células perfuradas em raios.

Fibras: Tecido fibroso proeminente, ocupando cerca de $51,6 \%$ do vo lume da madeira. Fibras libriformes, não septadas, frequentemente ge latinosas, com pontuações simples; muito curtas (666 - 828 - $1084 \mu \mathrm{m}$ ), estreitas $(7,5-11-15 \mu \mathrm{m})$ e de paredes muito espessas $\left(2,5-4,22^{-}\right.$ $6,3 \mu \mathrm{m})$.

Outros caracteres: Canais secretores, tubos lacticíferos e taninífe ros, líber incluso, máculas medulares e estratificação, ausentes.

Anēis de crescimento pouco perceptīveis ao microscópio, evidenciados pelo arranjo tangencial de poros no início do anel.

Cristais de oxalato de cālcio, presentes, não abundantes, em células procumbentes de raios.

Vasos radiais e séries de céluzas perfuradas de raio

Em raios de Colletia paradoxa são observadas células ra diais com espessamentos espiralados e placas de perfuração simples nas faces radiais da parede (Figura 2a). Estas cēlulas são verdadei ros elementos vasculares, não se distinguindo dos elementos vascula res axiais a não ser por sua localização, dimensões e origem.

As cēlulas perfuradas de raios são encontradas em Colzetia paradoxa frequentemente na extremidade dos mesmos, como pode ser vis to em plano longitudinal tangencial (Figura 2b). Deste modo, consti tuem uma ligação entre vasos longitudinais localizados em lados opos tos do raio.

Com bastante frequència vēem-se tambēm cēlulas radiais per furadas em sērie, constituindo um segmento tangencial de vaso que se comunica com dois vasos longitudinais, dispostos lateralmente ao raio (Figura 2c).

Em plano longitudinal radial podem tambēm ser observa das curtas sēries de cēlulas perfuradas de raio em direção radial (Figura 2d). Estes segmentos de vasos comunicam-se, também, com va sos longitudinais.

As cēlulas perfuradas de raio são menores do que os elementos vasculares axiais e tendem a formas mais isodiamétricas. A forma dos elementos vasculares radiais e sua localização em raios, indicam a origem a partir de cēlulas iniciais de raio, ao contrário dos elementos vasculares axiais, que derivam de células iniciais fu siformes.

DISCUSSÃO

Os vasos de colzetia paradoxa caracterizam-se por terem diaametro muito pequeno e serem compostos de elementos vasculares mui to curtos, com espessamentos espiralados e placas de perfuração sim ples. 

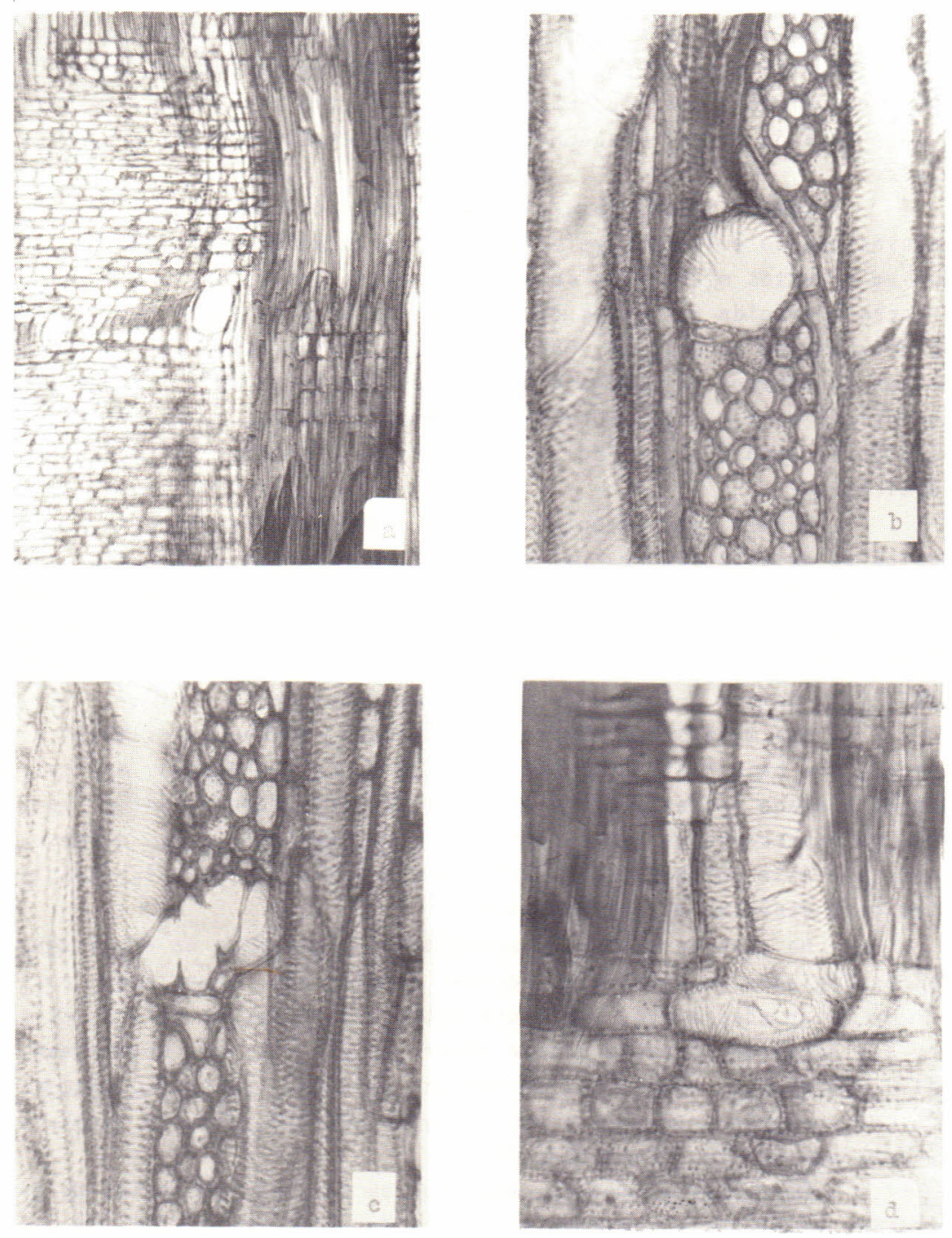

Figura 2. a, secção longitudinal radial $(78 \mathrm{X})$, mostrando células perfuradas de raio com placas de perfuração simples na fá ce radial da parede. b, secção longitudinal tangencial $(250 \mathrm{X})$, mostrando espessamentos espiralados em célula per furada da margem de raio multi-seriado. c, secção longitu dinal tangencial $(250 \mathrm{X})$, com segmento tangencial de vaso radial. d, secção longitudinal radial $(250 \mathrm{X})$, mostrando cēlulas perfuradas de raio em direção radial. 
Os vasos de Colletia paradoxa são de menor diāmetro den tro da famîlia Rhamnaceae. Esta característica, juntamente com o pe queno comprimento dos elementos vasculares, tem significado fisioló gico e está de acordo com a xeromorfia das espécies deste gênero bo tânico.

CARLQUIST (5) observou que vasos estreitos não são desvan tajosos quando é lenta a velocidade de condução da seiva, fato co mum em arbustos micrōfilos ou āfilos. Nestas condições, a maior fricção oferecida por vasos de pequeno diâmetro de seiva não se tor na desvantagem apreciāvel. Por outro lado, vasos estreitos resistem melhor às tensões na coluna d'ägua do que vasos de maior diâmetro, sendo, por este motivo, convenientes em plantas com baixa taxa trans piratōria, como è o caso de arbustos āfilos e plantas de regiões de sērticas.

WEBBER (16) encontrou que os elementos vasculares em ar bustos de deserto e chaparral são muito mais curtos e estreitcs do que na maioria das dicotiledōnias. Esta observação é compartilhada por NOVRUZOVA (9), em estudo de correlação entre ecologia e caracte rīsticas do sistema condutor de seiva em ārvores e arbustos, e CARL QUIST (4), para a anatomia da madeira em Asteraceae.

Nos mesmos trabalhos acima citados, Webber e Carlquist ex plicam, com base fisiológica, a presença de espessamentos espirala dos em elevada percentagem de arbustos xēricos. Segundo estes auto res, os espessamentos espiralados oferecem resistência ao colapso, sendo por este motivo, uma característica anatômica de valor adapta tivo para espēcies de regiões secas.

No caso de Colzetia, entretanto, a presença de espessamen tos espiralados em vasos não pode ser considerada apenas como cará ter de valor adaptativo, visto que estes ornamentos da parede celu lar são descritos para um grande nümero de gêneros de Rhamnaceae, tais como Adolia, Ceanothus, Colubrina, Condalia, Discaria, Doerpfel dia, Microrhamnus. Rhamnus e Sarcomphalus (RECORD, 11), em Scutia e em Zizyphus jujuba (SOLEREDER, 13).

Em Colzetia paradoxa não ocorrem cristais em sēries de pa rênquima axial. Esta característica foi descrita por $\operatorname{RECORD~(10),~co~}$ mo ocasional em madeiras deste gēnero. São abundantes, entretanto, monocristais romboēdricos de oxalato de cālcio em células de parên quima radial.

As características de raios, fibras e a pouca abundāncia de parēnquima axial em Colzetia paradoxa, concordam com as observa ções feitas por RECORD (10) para o gênero.

A ocorrência de cēlulas perfuradas na espécie em estudo é uma novidade para a família Rhamnaceae. 
As primeiras observações sobre a existência de vasos ra diais foram feitas por VLIET $(14 ; 15)$. em Combretaceae. BOTOSSO \& Go MES (1) descreveram diferentes tipos de vasos radiais encontrados em Annonaceae. A ocorrēncia deste carāter dentro do sistema de clas sificação vegetal ē ainda fragmentārio. Pouco se sabe, tambēm, sọ bre a ontogenia e formação dos elementos radiais de vasos. Parece haver, entretanto, uma tendência de formação deste tipo celular em espécies de raios altos, ou em plantas que experimentam elevadas tensões no sistema condutor de seiva. Para estas espécies, entre as quais presumivelmente se pode incluir a espécie estudada neste tra balho em virtude de sua notāvel xeromorfia, a interligação frequen te de vasos longitudinais paralelos, inclusive mediante a formação de segmentos de vasos radiais, é vantajosa para a continuidade do fluxo de seiva, porque possibilita a redução do efeito de eventuais colapsos em curtos segmentos do sistema condutor.

\section{REFERENCIAS BIBLIOGRÄFICAS}

1. BOTOSSO, P.C. \& GOMES, A.V. Radial vessels and series of perfo rated ray cells in Annonaceae. IAWA Buzletin, 3(1): 39-44, 1982.

2. BURGER, L.M. Estudo anatômico do xilema secundário de sete espé cies nativas do gênero Dalbergia, Leguminosae Faboideae.Curi tiba, Universidade Federal do Paranā. Curso de Pōs-Graduação em Engenharia Floresta1, 1979. $184 \mathrm{f}$. Tese de Mestrado.

3. BURKART, A. Leguminosas. In: CABRERA, A.L. Flora de Za Provincia de Buenos Aires. Buenos Aires, Col. Científica del INTA, 1967. Parte 3 : 394-647.

4. CARLQUIST, S. Wood anatomy of Compositae: a summary, with com ments on factors controlling wood evolution. Aliso, 6 (2) : 25-44. 1966 .

5. CARLQUIST, S. Ecological strategies of xylem evolution.Berkeley, University of California Press, 1975. 259 p.

6. COMISION PANAMERICANA DE NORMAS TECNICAS. 30:1-019, novembro, 1973.

7. LOMBARDO, A. Flora arborea y arborescente del Uruguay. Montevi deo, Concejo Departamental de Montevideo, s/d. 151 p.

8. METCALFE, C.R. \& CHALK, L. Anatomy of the Dicotyledons. Oxford, Clarendon Press, 1972. $1500 \mathrm{p}$.

9. NOVRUZOVA, Z.A. The water conducting system of trees and shrubs in relation to ecology. Baku, Izdal'stvo Akademii Nauk Azer baijan S.S.R. 1968 .

10. RECORD, S.J. American woods of the family Rhamnaceae. Tropical woods, 58: 6-24. 1939.

11. RECORD, S.J. Vessels with spiral thickenings. Tropical Woods, 73 , 
23-42. 1943.

12. RECORD, S.J. \& HESS, R.W. Timbers of the New World. New Haven, Yale University Press, 1943. $640 \mathrm{p}$.

13. SOLEREDER, H. Systematic Anatomy of the Dicotyledons. Oxford, 1908. $1183 \mathrm{p}$.

14. VLIET, G.J.C.M. van. Radial vessels in rays. IAWA Buzletin, 1976 3: $35-37.1976$.

15. VLIET, G.J.C.M. van. Wood anatomy of the Combretaceae. Blimea, 25: 141-223. 1979.

16. WEBBER, I.E. The woods of sclerophyllous and desert shrubs and desert plants of California. American Journal of Botany, 23 : $181-188.1936$.

Recebido em maio, 1983; aceito em junho, 1983. 